\title{
Extent of Post-traumatic Stress Disorder among Eastern Cape emergency care workers in the public health care sector
}

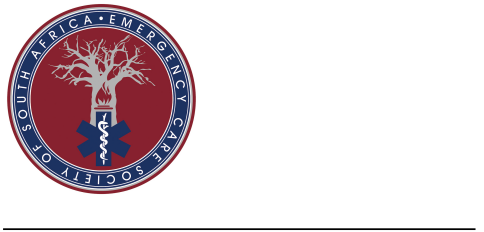

ARTICLE INFORMATION

Received: 19 March 2020

Revision received: 1 February 2021

Accepted: 10 February 2021

Keywords:

Pre-hospital Emergency Care Workers Post-traumatic Stress Disorder Emergency Medical Services

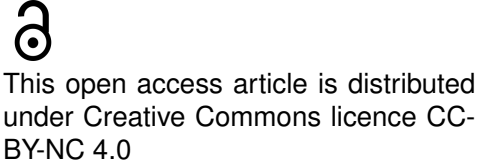

ISSN:2709-3786

\author{
Craig Visagie ${ }^{1}$, Luke van Tonder ${ }^{1}$, Ruwan Prinsloo ${ }^{1}$, Jared Surtees ${ }^{1}$, \\ Karin Gerber ${ }^{2,}$, Pieter Huysamen ${ }^{3}$ \\ ${ }^{1}$ Department of Emergency Medical Care, Nelson Mandela Univer- \\ sity \\ ${ }^{2}$ Department of Nursing Science, Nelson Mandela University \\ ${ }^{3}$ Eastern Cape College of Emergency Care
}

*Corresponding author: karin.gerber@mandela.ac.za, Nelson Mandela University, North Campus, Department of Nursing Science, University Way, Summerstrand, 6030, Gqeberha, South Africa

\section{ABSTRACT}

Background: Pre-hospital emergency care workers (PECWs) often struggle to cope with an increasingly hostile environment while on duty. As a result, the prevalence of post-traumatic stress disorder (PTSD) amongst PECWs is on the rise and negatively affects their ability to treat patients. Further, PTSD could cloud PECWs' clinical decision-making and judgement. This ultimately places strain on emergency care department's resources and directly affects patient care and service delivery. The aim of the study was to determine the extent to which PECWs experience PTSD symptoms in Nelson Mandela Bay (NMB).

Methods: A quantitative design and convenience sampling method were used. The research population for this study was all operational PECWs employed by the Eastern Cape Department of Health within the emergency medical services (EMS) in NMB. Data were collected by means of a self-administered questionnaire comprising two sections; the first section focused on respondent's demographic information, and the second section was a validated PTSD questionnaire. Descriptive and inferential statistics were reviewed using Microsoft Excel.

Results: Sixty-eight PECWs took part in the study. It was identified that of the 68 respondents, 41 (60.3\%) showed symptoms of PTSD and could possibly be diagnosed with PTSD. The mean PTSD score was $42.01 \pm 17.35$, ranging in the category of 'possible diagnosis of PTSD'. The highest mean PTSD scores were reported among respondents who identified themselves as female $(p<0.001)$. Those within the age category of 51-60 years, those who were Advanced Life Support (ALS) practitioners, and those with 20 years or more work experience also had high mean PTSD scores.

Conclusion: PTSD remains a burden on both the individual and the organisation employing the individual. This study highlighted that many PECWs employed in the Eastern Cape public health care sector showed symptoms and could be diagnosed with PTSD, with female PECWs being at the highest risk.

Visagie C, van Tonder L, Prinsloo R, Surtees J, Gerber K, Huysamen P. Extent of Post-traumatic Stress Disorder among Eastern Cape emergency care workers in the public health care sector. South African Journal of Pre-hospital Emergency Care. 2021; 2(1):11-17. doi:10.24213/2-1-3963 


\section{BACKGROUND}

Pre-hospital emergency care workers (PECWs) are exposed to numerous stressors from varying sources that are part of the emergency care environment. Stressors include being exposed to disturbing scenes, witnessing the loss of human life and workplace violence. ${ }^{1}$ However, stressors are not always tied to PECWs' experiences of traumatic incidents. The emergency care environment shares issues that affect other work environments, such as harassment from colleagues, physical injury, as well as a lack of supervisory support. ${ }^{1}$ Frequent and repeated exposure to these stressors compound, and the inability to cope with these stressors can lead to post-traumatic stress disorder (PTSD) ${ }^{1,2}$ PTSD is defined as an anxiety disorder that occurs in response to experiencing accidents and events accompanied by fear and frustration. The core symptoms of PTSD are disturbing and undesirable images and memories of traumatic incidences, and behavioural avoidance from the signs that remind a person of those events; PTSD also typically weakens the normal professional functioning of the affected person. ${ }^{3,4}$ Workers who experience poor working conditions, severe injuries, have a history of mental disorder, psychiatric symptoms at the time of the event, and experience a lack of resilience and social support are particularly at risk for PTSD. ${ }^{5,6}$ The prevalence of PTSD among emergency care workers has been estimated to be between 10 and $17 \%$, which is higher than the overall population (approximately $6.8 \%){ }^{7}$ If PECWs are not supported to deal with PTSD, delays in treatment could further escalate. Moreover, the symptoms of PTSD, which vary but could include chronic physical illnesses involving inflammatory diseases, impairment in social and occupational functioning, substance abuse, emotional blunting and detachment, may result in absenteeism and the risk for loss of income. ${ }^{8}$

Studies in sub-Saharan Africa determined a high prevalence of PTSD in the region, yet research on the phenomenon remains scarce. ${ }^{9}$ PECWs in South Africa experience high levels of stress since they attend gruesome scenes, experience extreme pressure to save lives, and sometimes attend a scene where a child or a colleague is involved. ${ }^{10}$ One South African study on trauma exposure, PTSD, and the effect of explanatory variables among 131 paramedic trainees found that $94 \%$ of paramedic trainees had directly experienced trauma, with $16 \%$ meeting PTSD criteria. A high rate of depression $(28 \%)$, alcohol abuse $(23 \%)$, chronic perceived stress $(7 \%)$, and low levels of social support were also reported. ${ }^{6}$ Another South African study found that critical incident exposure and rates of general psychopathology among South African emergency service personnel were higher than in studies in the developed world. Exposure to critical incidents was associated with symptoms of PTSD, reiterating that service organisations should provide appropriate support in terms of debriefing or counselling, which is often lacking, and PECWs should be trained to prepare for the emotional fallout from traumatic incidents. ${ }^{11,12}$ No previous research has been conducted regarding PTSD among PECWs in NMB. Therefore, the purpose of this study was to determine the extent to which PECWs experience PTSD symptoms in NMB.

\section{DESIGN AND METHODS}

\section{Study Design}

The research design used for the study was a quantitative inquiry to determine the extent to which PECWs in NMB were experiencing PTSD symptoms.

\section{Setting}

The study was conducted at one public emergency medical service (EMS) station, situated in an urban area in NMB. This station served a population of approximately $1,254,000$ people. $^{13}$

\section{Study Population and Sample}

The research population was 100 PECWs employed by the Eastern Cape Department of Health at the NMB EMS station. PECWs in South Africa include the following three categories: Basic Ambulance Assistants (BAA), Ambulance Emergency Assistants (AEA), and Advanced Life Support (ALS) practitioners. ALS practitioners include Emergency Care Technicians, Critical Care Assistants, National Diploma Paramedics, and Emergency Care Practitioners (bachelor's-degree holders).

Convenience sampling was implemented. It is a cost-effective method to access the sample population and obtain a sample size as large as possible to conduct appropriate analyses. Through convenience sampling, all active-duty PECWs from all four shifts (each shift had 20-25 active-duty staff members) were included in the sample.

\section{Data Collection Instrument}

Data were collected by means of a selfadministered questionnaire consisting of two sections. The first section focused on respondents' demographic information, and the second section was a PTSD questionnaire (PTSS-10). The questionnaire was presented in English.

The demographics section of the questionnaire 
contained questions on the respondents gender, age, highest qualification and work experience. The second component of the questionnaire was the PTSS-10, which measures the intensity of PTSD symptoms (intrusion, avoidance, hyper-alertness) according to the criteria in the Diagnostic and Statistical Manual of Mental Disorders 5 (DSM-5). ${ }^{14}$ The DSM- 5 was designed by the American Psychiatric Association as a tool to investigate and aid in the diagnoses of PTSD and other mental health illnesses, and was used in a large meta-analysis study conducted in 2010. ${ }^{14,15}$ The tool has shown satisfactory psychometric properties with a high internal consistency (Cronbach's alpha > .90), a sensitivity of $77 \%$, and a specificity of $97.5 \%$ for the diagnosis of PTSD. ${ }^{15}$

The DSM-5 uses a Likert-type scale scoring system composed of 20 questions relating to PTSD symptoms. The respondent could select a numerical value on a Likert scale $(0=$ Not at all, $1=\mathrm{A}$ little bit, 2= Moderately, 3= Quite a bit, and 4= Extremely) indicating the frequency with which they experienced the feeling or symptom within the last month. Respondents could have a minimum score of 0 and a maximum score of 80 ; a score of 80 would indicate a high probability of PTSD (adapted from the Department of Veteran Affairs). ${ }^{16}$ However, a possible diagnosis can be made should the respondent have a total score of 40 or above, and further psychological investigation is required for any score over $33 .{ }^{16}$

\section{Data Collection}

After permission was provided by the EMS station manager to approach the PECWs during working hours, the researchers verbally shared information about the study with prospective respondents during the handover of each of the four shifts. All staff who were willing to participate were given a consent letter stating the reason for the research and informing them of their rights. After completing the consent letters, which were returned to the researchers, the self-reported questionnaire was distributed. The respondents then returned the completed questionnaire to a sealed box that was only accessible to the researchers.

No pilot study was required as the PTSS-10 data collection instrument had been verified in previous studies. ${ }^{17}$ The questionnaire was contextualised through a review by experts in the South African public EMC setting. No changes had to be affected after it was reviewed.

\section{Data Analysis}

The data were captured on a Microsoft Excel spreadsheet. Descriptive and inferential statis- tics were employed to depict the extent of PTSD symptoms among the sample. The calculation was adapted from the Department of Veteran Affairs16 as follows: using the numerical values attached to each question from the Likert scale on each completed questionnaire, a total score was attributed to each question. The maximum score for the entire data set that could be assigned to any question was 80 , and the minimum could be 0 . For the purpose of this study, all respondents who scored 40 or higher on the PTSS-10 questionnaire were grouped together as showing symptoms of PTSD and requiring a possible PTSD diagnosis. Oneway ANOVA was conducted to determine statistically significant differences between the demographic groups. Moreover, Chi-square tests were performed to determine the statistical significance of the relationships between demographic variables and respondents' categorised PTSD scores.

\section{Ethical Considerations}

Before the study was conducted, ethical clearance was obtained from the Human Research Ethical Council (REC-H) (H19-HEA-EMC-002) and the National Health Research Database (NHRD) (EC201908-004).

The nature, risks and potential benefits of the study were explained to the respondents. The only potential risk of participating in the study was that, by answering the questions, the respondent could be triggered to recollect a traumatic event. Counselling was made available for those who required this intervention. Respondents were asked to sign an informed consent document to acknowledge that they understood the purpose of the research and their rights.

Respondents were not required to fill in their name, surname, postal address or residential address on any part of the questionnaire. The respondents were asked whether they would like to complete a questionnaire, and no one was coerced to take part in the study. The respondents' right to withdraw from the study at any given time and without any consequences was also emphasised to prospective respondents. If the respondent wanted to withdraw from the study, they did not have to report it but merely did not hand in their questionnaire.

\section{RESULTS}

Sixty-eight PECWs participated in the study, which resulted in a response rate of $68 \%$. 


\section{Demographics}

The respondents' demographics are outlined in Table 1 . The majority of respondents were male $(n=43,63.2 \%)$, between the ages of $41-50$ years $(n=22,32.4 \%)$ and $31-40$ years $(n=21,30.9 \%)$. The
68 respondents' levels of medical qualification all varied, with the majority being AEA ( $n=41,60.3 \%)$. More than one-third of the respondents had 11-15 years' work experience $(n=26,38.2 \%)$, followed by those with $6-10$ years' work experience $(n=21$, $30.9 \%)$.

Table 1: Participant Demographics $(n=68)$

\begin{tabular}{ll}
\hline Gender & $\mathbf{n ~ ( \% )}$ \\
\hline Male & $43(63.2)$ \\
Female & $25(36.8)$ \\
\hline Age (years) & $\mathbf{n ~ ( \% )}$ \\
\hline$<20$ & 0 \\
$21-30$ & $11(16.1)$ \\
$31-40$ & $21(30.9)$ \\
$41-50$ & $22(32.4)$ \\
$51-60$ & $14(20.6)$ \\
$>60$ & 0 \\
\hline Highest Qualification & $\mathbf{n ~ ( \% )}$ \\
\hline Basic Ambulance Assistant & $23(33.8)$ \\
Ambulance Emergency Assistant & $41(60.3)$ \\
Emergency Care Technician & $1(1.5)$ \\
Emergency Care Practitioner & $3(4.4)$ \\
\hline Work Experience (years) & $\mathbf{n ( \% )}$ \\
\hline $1-5$ & $10(14.7)$ \\
$6-10$ & $21(30.9)$ \\
$11-15$ & $26(38.2)$ \\
$16-20$ & $3(0.04)$ \\
$>20$ & $8(11.8)$ \\
\hline
\end{tabular}

\section{PTSD Scores}

As per the DSM-5, if respondents scored between 33 and 39, further investigation is required to determine whether they have possible PTSD. If respondents scored over 40, the DSM-5 states that a possible diagnosis of PTSD can be made. Table 2 indicates respondents PTSD scores according to the three categories.

Table 2: PTSD Scores

\begin{tabular}{ll}
\hline PTSD Score Categories & $\mathbf{n}(\mathbf{\%})$ \\
\hline$\leq 32$ (no PTSD) & $22(32.3)$ \\
33-39 (further investigation req.) & $5(7.4)$ \\
$>40$ (possible diagnosis of PTSD) & $40(60.3)$ \\
\hline
\end{tabular}

As reflected in Table 2, of the 68 respondents, 41 scored more than 40 on the DSM-5 questionnaire, indicating that a possible PTSD diagnosis could be made for $60.3 \%$ of the respondents. Further, the overall mean PTSD score was 42.01 , with a standard deviation of 17.354, ranging in the possible diagnosis of PTSD category.

\section{PTSD Scores and Demographics}

Table 3 illustrates the mean PTSD scores per demographic factor, as well as the p-value between demographic categories.

As depicted in Table 3, the highest mean PTSD scores were among female respondents, those within the age category of 51-60 years, those who were ALS practitioners, and those with 20 years or more work experience. The PTSD mean scores between male and female respondents showed significance $(\mathrm{p}<0.001)$. 
Table 3: Participant Demographics $(n=68)$

\begin{tabular}{lll}
\hline Gender & Mean PTSD Score (SD) & $\mathbf{p}$ \\
\hline Male $(\mathrm{n}=43)$ & $31.91(12.79)$ & $<0.001$ \\
Female $(\mathrm{n}=25)$ & $59.40(7.52)$ & $\mathbf{p}$ \\
\hline Age (years) & Mean PTSD Score (SD) & 0.87 \\
\hline $21-30(\mathrm{n}=11)$ & $41.25(22.71)$ & \\
$31-40(\mathrm{n}=21)$ & $42.62(18.07)$ & \\
$41-50(\mathrm{n}=22)$ & $40.05(17.26)$ & $\mathbf{p}$ \\
$51-60(\mathrm{n}=24)$ & $45.08(11.16)$ & 0.450 \\
$>60$ & 0 & $\mathbf{p}$ \\
\hline Highest Qualification & Mean PTSD Score (SD) & \\
\hline Basic Ambulance Assistant $(\mathrm{n}=23)$ & $39.17(17.81)$ & 0.095 \\
Ambulance Emergency Assistant $(\mathrm{n}=41)$ & $42.41(17.41)$ & \\
Advanced Life Support $(\mathrm{n}=4)$ & $53.00(11.53)$ & \\
\hline Work Experience (years) & Mean PTSD Score (SD) & \\
\hline $1-5(\mathrm{n}=10)$ & $29.50(21.26)$ & \\
$6-10(\mathrm{n}=21)$ & $44.48(17.75)$ & \\
$11-15(\mathrm{n}=26)$ & $42.00(16.42)$ & \\
$16-20(\mathrm{n}=3)$ & $43.75(12.45)$ & \\
$>20(\mathrm{n}=8)$ & $51.57(6.60)$ & \\
\hline
\end{tabular}

\section{DISCUSSION}

Based on the findings, the PECWs in this study had mean PTSD scores that can be categorised as a 'possible diagnosis of PTSD'. High mean PTSD scores were more prevalent among female respondents than their male counterparts in this study. The same finding is reported in a study that examined the prevalence of PTSD based on gender; it was found that PTSD prevalence was $5-6 \%$ among men, while it was $10-12 \%$ among women. ${ }^{18}$ Pooley and colleagues ${ }^{19}$ concluded that women show fundamental differences in response to traumatic events, and this could explain why women scored higher for PTSD than men.

From the literature, it seems that men and women are differently affected by PTSD. ${ }^{20}$ For example, a study found that the highest prevalence of PTSD was among men in their early 40 s and women in their early 50s. ${ }^{21}$ In this study, the mean PTSD score was the highest for those respondents between 51 and 60 years; however, the study did not determine any significance regarding age.

The findings showed that the mean score of PTSD was the highest for ALS practitioners, although our study did not find any statistical significance in this regard. Iranmanesh, Tirgari and Badsiri ${ }^{22}$ and Stewart and Swartz ${ }^{23}$ reported similar findings as they did not find a positive correlation between medical qualification and the presence of PTSD. sure to traumatic events is a predisposing risk factor in developing PTSD. Based on the effects of chronic exposure to traumatic events, the assumption would be that more years of service would result in a higher prevalence and incidence of PTSD, as found in other studies. ${ }^{24,25}$ As such, it can be assumed that years of service could have influenced on PTSD symptoms. This study had similar findings, as those respondents with $20<$ years of working experience had the highest mean PTSD scores. However, this score was not found to be significant. Further, the individual's personality and resilience to cope with traumatic experiences were also found to influence PTSD. ${ }^{26,27}$ As this study did not investigate these variables, this warrants further exploration in the setting where the research was conducted.

More than half of the respondents could potentially be diagnosed with PTSD as they rated similarly on questions related to their emotions and responses when they were reminded of a traumatic event. However, the frequency and type of trauma experienced were not measured in this study. Future studies should be conducted to explore the relationship between PTSD, the level of trauma and demographic factors such as age, level of medical qualification, years of work experience, and other factors that could influence PTSD, including personality and resilience.

According to Stewart and Swartz, ${ }^{23}$ chronic expo- 


\section{LIMITATIONS}

The DSM-5 questionnaire used in this study could not provide a definitive diagnosis of PTSD but could only offer a possible diagnosis for respondents who scored 40 or higher on the questionnaire. Further psychological evaluation is required to confirm the diagnosis of PTSD amongst NMB PECWs and the true extent of possible PTSD among the sample.

Generalisability is a potential limitation of convenience sampling. Another limitation includes participant bias because data of a sensitive nature, namely PTSD, was explored. Further, the small sample size, the restricted geographical location, and the fact that only employees from the public health sector were included may potentially have led to under- or over-representation of certain aspects of the research population. The results can therefore not effectively be generalised to the research population.

\section{CONCLUSION}

The study highlighted the extent of possible PTSD among operational staff at NMB EMS. With $60.3 \%$ of the sample scoring 40 or higher on the DSM5 PTSD questionnaire, and an overall mean PTSD score of 42 , it is evident that a large number of operational NMB PECWs may be affected by PTSD. Women seemed to be more affected by PTSD as they scored significantly higher than the male respondents in this study. Further exploration is required to establish whether there is a correlation between PTSD, the level of trauma, as well as demographics and other factors that could influence PTSD in this population.

PECWs should be better informed about the signs and symptoms of PTSD and how they can build resilience. Mental health services should be made accessible to all PECWs, and regular screening for possible signs and symptoms of PTSD should be encouraged.

\section{ACKNOWLEDGMENT}

The researchers thank the Eastern Cape Department of Health and the NMB Metro Ambulance Services for permitting them to conduct the study within their premises.

\section{CONFLICTS OF INTEREST}

The authors report no conflicts of interest.

\section{AUTHOR CONTRIBUTIONS}

All authors contributed to conceptualisation of the research, data collection, data analysis, drafting and revision of the manuscript and final approval of the manuscript.

\section{REFERENCES}

1. Haugen PT, Evces M, Weiss DS. Treating posttraumatic stress disorder in first responders: a systematic review. Clin Psychol Rev. 2012;32:370-80.

2. Donnelly E. Work-related stress and posttraumatic stress in emergency medical services. Prehosp Emerg Care. 2012;16:76-85.

3. Lancaster CL, Teeters JB, Gros DF, Back SE. Posttraumatic Stress Disorder: Overview of Evidence-Based Assessment and Treatment. J Clin Med. 2016;5.

4. Thibaut F. Anxiety disorders: a review of current literature. Dialogues Clin Neurosci. 2017;19:87-8.

5. Lee W, Lee YR, Yoon JH, Lee HJ, Kang MY. Occupational post-traumatic stress disorder: an updated systematic review. BMC Public Health. 2020;20:768.

6. Fjeldheim CB, Nöthling J, Pretorius K, et al. Trauma exposure, posttraumatic stress disorder and the effect of explanatory variables in paramedic trainees. BMC Emerg Med. 2014;14:11.

7. Berger W, Coutinho ES, Figueira I, et al. Rescuers at risk: a systematic review and metaregression analysis of the worldwide current prevalence and correlates of PTSD in rescue workers. Soc Psychiatry Psychiatr Epidemiol. 2012;47:1001-11.

8. Reinecke C. Beyond vicarious trauma: Exploring adversarial growth in a sample of South African paramedics. Thesis. Stellenbosch University, 2017.

9. Ng LC, Stevenson A, Kalapurakkel SS, et al. National and regional prevalence of posttraumatic stress disorder in sub-Saharan Africa: A systematic review and meta-analysis. PLoS Med. 2020;17:e1003090.

10. Zana T. Competencies needed to prepare Intermediate Life Support (ILS) paramedics in Gauteng to manage traumatic stress in the work environment. Dissertation. University of Cape Town, 2019. 
11. Ward CL, Lombard CJ, Gwebushe N. Critical incident exposure in South African emergency services personnel: prevalence and associated mental health issues. Emerg Med J. 2006;23:226-31.

12. Minnie L, Goodman S, Wallis L. Exposure to daily trauma: The experiences and coping mechanism of emergency medical personnel. A cross-sectional study. Afr J Emerg Med. 2015;5:12-8.

13. Nelson Mandela Bay Metro Municipality Socio Economic Review and Outlook. Eastern Cape Socio-economic Consultative Council, 2017. (https : / / www . ecsecc . org / documentrepository / informationcentre/nelson-mandelabay-metro-municipality_31887.pdf) (visited on 02/01/2021).

14. American Psychiatric Association. Diagnostic and statistical manual of mental disorders: dsm-5. Fifth. Washington D.C.: APA, 2013.

15. Yufik T, Simms LJ. A meta-analytic investigation of the structure of posttraumatic stress disorder symptoms. J Abnorm Psychol. 2010;119:764-76.

16. PTSD Checklist for DSM-5 (PCL-5). US Dept of Veteran Affairs., 2013. (https : / / www . ptsd . va . gov / professional / \%20assessment / adult - sr / ptsd checklist.asphttps://www.ptsd.va. gov / professional / \%20assessment / adult-sr/ptsd-checklist . asp) (visited on $04 / 22 / 2018$ ).

17. Stinchfield R, McCready J, Turner NE, et al. Reliability, Validity, and Classification Accuracy of the DSM-5 Diagnostic Criteria for Gambling Disorder and Comparison to DSMIV. J Gambl Stud. 2016;32:905-22.

18. Olff M. Sex and gender differences in posttraumatic stress disorder: an update. Eur J Psychotraumatol. 2017;8:1351204.
19. Pooley AE, Benjamin RC, Sreedhar S, et al. Sex differences in the traumatic stress response: PTSD symptoms in women recapitulated in female rats. Biol Sex Differ. 2018;9:31.

20. Kobayashi I, Sledjeski EM, Delahanty DL. Gender and age interact to predict the development of posttraumatic stress disorder symptoms following a motor vehicle accident. Psychol Trauma. 2019;11:328-36.

21. Ditlevsen DN, Elklit A. The combined effect of gender and age on post traumatic stress disorder: do men and women show differences in the lifespan distribution of the disorder? Ann Gen Psychiatry. 2010;9:32.

22. Iranmanesh S, Tirgari B, Bardsiri HS. Posttraumatic stress disorder among paramedic and hospital emergency personnel in southeast Iran. World J Emerg Med. 2013;4:26-31.

23. Stewart J, Swartz L. Post-traumatic stress symptoms in emergency service ambulance personnel. Social Work. 2014;41:362-77.

24. Eiche C, Birkholz T, Jobst E, Gall C, Prottengeier J. Well-being and PTSD in German emergency medical services - A nationwide cross-sectional survey. PLoS One. 2019;14:e0220154.

25. Kerai S, Pasha O, Khan U, Islam M, Asad N, Razzak J. Association of post-traumatic stress disorder and work performance: A survey from an emergency medical service, Karachi, Pakistan. World J Emerg Med. 2017;8:214-22.

26. Duan W, Guo P, Gan P. Relationships among Trait Resilience, Virtues, Post-traumatic Stress Disorder, and Post-traumatic Growth. PLoS One. 2015;10:e0125707.

27. Bensimon M. Elaboration on the association between trauma, PTSD and posttraumatic growth: The role of trait resilience. Pers Individ Dif. 2012;52:782-7. 